Brazilian Journal

of Chemical

Engineering

\title{
THERMODYNAMIC ANALYSIS AND MODELING OF BRAZILIAN CRUDE OIL AND ASPHALTENE SYSTEMS: AN EXPERIMENTAL MEASUREMENT AND A PC-SAFT APPLICATION
}

\author{
Natalia Neuhaus ${ }^{1}$, Priscila T. H. Nascimento ${ }^{1}$, Isabele Moreira ${ }^{1}$, \\ Agnes P. Scheer ${ }^{1}$, Alexandre F. Santos ${ }^{1 *}$ and Marcos L. Corazza ${ }^{1}$ \\ ${ }^{1}$ Universidade Federal do Paraná, Departamento de Engenharia Química, Curitiba, PR, Brasil. E-mail: alexfsantos@ufpr.br, \\ ORCID: 0000-0001-5885-3637; ORCID: 0000-0002-2874-5595; ORCID: 0000-0003-2305-1989
}

(Submitted: November 10, 2017 ; Revised: February 4, 2018 ; Accepted: February 9, 2018)

\begin{abstract}
Asphaltenes represent the heaviest fraction of crude oils, being recognized by their tendency to self-associate and precipitate. Asphaltene precipitation and subsequent deposition can cause problems in all stages of production. The objective of this paper is to model Brazilian crude oil and asphaltene systems using the PC-SAFT equation of state. Asphaltenes were extracted from crude oil through the addition of different n-alkanes. The PC-SAFT was capable of accurately predicting liquid density for toluene and asphaltenes and boiling point elevation for crude oil at different concentrations of toluene. Asphaltene precipitation from model oil allowed us to evaluate the influence of binary interaction parameters on modeling results. The influence of precipitant agent (n-hexane and n-heptane) on the asphaltene phase behavior was analyzed, showing that n-hexane was able to precipitate more asphaltenes than n-heptane, as expected. Furthermore, simulated results are in agreement with experimental observations: the average relative errors are $3.75 \%$ and $10.25 \%$ for the weight percentage of precipitated asphaltene using n-hexane and n-heptane as precipitant, respectively.

Keywords: Brazilian crude oil; Asphaltene precipitation; PC-SAFT.
\end{abstract}

\section{INTRODUCTION}

Petroleum is still the largest source of total primary energy. The global demand in 2017 is projected at approximately 97.9 million barrels per day, a forecasted growth of 1.3 million barrels per day. This increase in the production involves the exploitation of new reservoirs, including heavy crude oil reservoirs, which impose a number of operational challenges.

Crude oil is a complex mixture of hydrocarbons and other organic compounds containing heteroatoms, such as oxygen, nitrogen, sulphur and metallic constituents. These species are commonly classified into four main fractions: saturates, aromatics, resins and asphaltenes. This classification is known as the
SARA characterization (Nascimento et al., 2016; Santos et al., 2014; Sabeti et al., 2015; Mullins, 2007; Merino-Garcia and Andersen, 2004) and is based on operational procedures associated with solubility and adsorption. The SARA method is reproducible and applicable to a wide variety of oils and bitumen, shale and petroleum residues (Santos et al., 2014).

Asphaltenes, polydisperse molecules of polar and heavy oil components, are often insoluble in n-alkane (n-pentane and n-heptane) and highly soluble in an aromatic solvent (benzene and toluene )(Mousavi-Dehghani et al., 2008). Over the decades, there has been an intense debate with respect to its chemical composition, structure and molecular weight (Quintero, 2009). The number of species with very

\footnotetext{
* Corresponding author: Alexandre F. Santos - E-mail: alexfsantos@ufpr.br
} 
different characteristics inside the asphaltene fraction is statistically estimated to be over 100,000 (Sabeti et al., 2015). Moreover, it contains a high proportion of aromatic rings, heteroatoms $(\mathrm{C}, \mathrm{H}, \mathrm{N}, \mathrm{O}$ and $\mathrm{S})$ and some metal constituents (Fe, $\mathrm{Ni}$ and $\mathrm{V})$ (Speight, 2006). The removal of metals increases the rate of dissolution or, in other words, the metal content has a direct effect on asphaltene dissolution, being important in the self-association of asphaltenes (Kaminski, 2000). Asphaltene molecular weight ranges from 500 to $2000 \mathrm{~g} / \mathrm{mol}$ (Nascimento et al., 2016) depending not only on the oil and its origin, but also depending on the nature of the solvent, the solution temperature, the preliminary treatment and the measurement method (Quintero, 2009).

Field operations are facing problems caused by the tendency of asphaltenes to associate and precipitate, causing several costly operational problems (Vargas et al., 2009). Asphaltene precipitation or its solubilization is a consequence of pressure, temperature or composition variation (Rajagopal and Silva, 2004). Deposition of asphaltenes can cause several problems in all stages of production (Gholami et al., 2014; Kord et al., 2012), including oil production and recovery, due to mechanisms of wettability alteration and blockage (Salahshoor et al., 2013), as well as in both downstream operations, where they can block pipelines and equipments, and upstream operations, since asphaltenes are deposited in rocks, reducing their porosity and permeability (Kazeem et al., 2012). Asphaltene deposition and flow restrictions are also observed during light oil production, with low asphaltene content (Cardoso et al., 2014). A necessary condition for the deposition of asphaltenes on surfaces is their precipitation, described by bulk phase equilibrium thermodynamics (Li and Firoozabadi, 2009), although in some cases the deposition may not occur. Deposition is related to surface characteristics, to the flow field in the system and to both the amount and the properties of precipitated asphaltenes (Vargas et al., 2014; Li and Firoozabadi, 2009).

Temperature influence on asphaltene solubility is under investigation and different conclusions have been described. Nevertheless, there is a consensus in the literature that the effect of temperature is negligible compared to other parameters such as pressure (Moradi et al., 2012; Verdier et al., 2006). As the asphaltene molecules are quite distinct, depending on the oil origin and the precipitation conditions, it is difficult to characterize them. Also, with the addition of another component, such as carbon dioxide, the unstable region will also be affected by changing the proximity of the critical region of the system. Thiyagarajan et al. (1995) claimed that, as the temperature increased, the length of the aggregates decreased, while Moritis (2001) affirmed that asphaltenes have been precipitated during transportation when the temperature was decreased. According to Vargas et al. (2009) and Gonzalez et al. (2005) in systems containing molecules with large differences of molecular weights, asphaltene precipitation decreases until a certain temperature and then starts to increase. They explained that, at low temperatures, the differences in interaction energies between solvent (crude oil) and asphaltene molecules make asphaltenes unstable, increasing the amount of asphaltenes precipitated. As temperature increases, the large thermal expansivity of the solvent compared to that of asphaltene ensures the solution splits and causes the precipitation of asphaltenes. Verdier et al. (2006) used $\mathrm{CO}_{2}$ as a precipitant to study the effects of temperature on the stability of asphaltenes from two different crude oils and found that, for both oils, a decrease in temperature leads to an increase in the solubility of asphaltenes. The authors justified these controversial observations by simple principles of thermodynamics like Le Châtelier's principle and solubility parameters.

Influence of pressure on asphaltene precipitation is a consensus among the authors and occurs in a delimited region known as the asphaltene deposition envelope (ADE) (Sabeti et al., 2015; Vargas et al., 2009; Verdier et al., 2006). For instance, Sabeti et al. (2015) presented the P vs. mole of solvent qualitative diagram for an oil sample at a constant temperature, providing an interesting guide of bubble points and asphaltene onset pressures. At high pressure, above the bubble point, the asphaltenes are soluble in oil and, as the pressure drops, especially for crude oils containing high fractions of saturates, the oil expands and reduces the oil solubility parameters, becoming a poor asphaltene solvent. During the oil recovery, the system continues to depressurize until it reaches the bubble point. At this point, the light constituents (asphaltene precipitants) escape to the gas phase, increasing the solubility parameters and the oil becomes a good asphaltene solvent again. Ting, Hirasaki and Chapman (2003) showed that asphaltenes are unstable below a certain solubility parameter of the oil, while Vargas et al. (2009) found the solubility parameter is not always constant along the asphaltenes stability boundary.

The complex structure of asphaltenes and the mechanism of precipitation and stabilization have been continuously discussed over the years. Two models were proposed for asphaltene stabilization in crude oil: colloidal and solubility theories. The classic colloidal theory given by Pfeiffer and Saal (1940), inspired in part by Nellensteyn (1924), assumes that asphaltene and resin are polar molecules. In this model, asphaltene molecules are present in the crude oil as solid particles and are stabilized by the resins adsorbed on their surface (micelle formation). Therefore, when the resins are removed from the surface, by dilution 
with alkanes or any other diluent, the asphaltenes are not soluble in the resulting oil mixture, forming a separate phase. However, Czarnecki (2009) illustrated using a hydrophilic-lipophilic balance that asphaltenes are not polar and do not form micelles.

On the other hand, in the solubility model or molecular model, asphaltenes are stabilized by the oil and their precipitation can be modeled as solid-liquid or liquid-liquid equilibrium (Alhammadi et al., 2015; Sedghi and Goual, 2004). Two pseudo components (asphaltene and solvent) form the crude oil and their phase behavior is determined by molecular size and van der Waal interactions. Nowadays, the solubility model has been the focus of a number of researches. Two main types of models have emerged from this theory: (1) regular solution models that use FloryHuggins theory, and (2) equation of state (EOS) models (Li and Firoozabadi, 2009; Pfeiffer, 1940). The Flory-Huggins approach is able to successfully predict both the onset and the amount of asphaltene precipitate, but it does not consider the asphaltene association and the compressibility effect on phase behavior that is estimated by the EOS approach. Mousavi-Dehghani, Mirzayi and Vafaie-Sefti (2008) developed a new method based on Flory-Huggins theory for modeling of asphaltene precipitation during natural depletion and miscible gas injection and got good predictions. Although the cubic EOS require fairly simple calculations and have been used to predict the thermodynamic behavior of fluids on reservoir conditions, they, unlike the non-cubic equations, neither precisely describe systems of phase behavior with large gaps, nor the density of liquids (Vargas et al., 2009). As for the non-cubic equations, a modern equation of state based on statistical theory and all their versions give a good prediction for the phase behavior of high-molecular-weight fluids: the statistical associating fluid theory (SAFT) model.

Using statistical mechanics and hard sphere systems with the hypothesis that monomers and dimers, including their possible aggregates, should be treated as distinct chemical entities, Wertheim (1984a, 1984b, 1986a, 1986b) introduced a breakup of the pair potential into repulsive and highly directionally attractive parts into fugacity graphs, promoting association into dimers and possible higher $s$-mers (Holavko and Kalyuzhnyi, 1991). Thus, molecules are treated as different species according to the number of bonded associating sites and the fugacity is replaced by two variables: the usual single density and the density of monomers (Alhammadi et al., 2015; Holavko and Kalyuzhnyi, 1991). This theory resulted in an equation that describes the variation of residual Helmholtz free energy depending on the monomer density (Ghonasgi and Chapman, 1993) instead of as a function of the single density, as in classical fluid theory. The advantage of the Wertheim theory is not only that it allows any approximation made in the theory to be tested using computer simulation, but also that it provides excellent results without requiring either chemical reactions or equilibrium constants in the temperature-dependent equations (Muller and Gubbins, 1989).

Chapman et al. $(1988,1989,1990)$ transformed the abstract Wertheim's first-order perturbation theory into a feasible engineering equation of state (von Solms, 2004) for chain molecules, known as Statistical Association Fluid Theory (SAFT). According to Ndiaye et al. (2006), the success of the SAFT EoS is due to the better modeling of molecules, considered to be a collection of spherical segments with repulsive (hard-sphere) and attractive (dispersion) force fields. At the beginning of the processes involved in SAFT to form a molecule from individual contribution, it is assumed that the pure fluid is an individual hard spherical segment. As a dispersive potential is added, an attraction force occurs between the spheres until a chain is formed. Finally, there is the chain association, due to some attractive interaction (hydrogen bonding). For a better understanding, Muller and Gubbins (2001) provided a scheme presenting an alkane molecule, as shown in Figure 1, with $m$ spherical segments composing the aliphatic chain, each of them corresponding to a united atom group. The rightmost sphere corresponds to an oxygen-containing segment with two associating sites, accounting for the proton and the electron pair. The perturbed chain theory represents the interactions of molecules in two parts: the first one is the repulsive contribution, described by Chapman et al. (1988) with a hard-chain equation, and the second is the attractive contribution, further divided into dispersive and associative interactions. Thus, the free energy of a fluid, known as Helmholtz free energy, is calculated by the contribution of each of these steps, given by Equation 1:

$\mathrm{a}^{\text {res }}=\mathrm{a}^{\text {seg }}+\mathrm{a}^{\text {chain }}+\mathrm{a}^{\text {assoc }}$

where $\mathrm{a}^{\text {seg }}$ is the free energy of the individual monomeric spherical "segments", $a^{\text {chain }}$ is the change in free energy due the chain formation and $\mathrm{a}^{\text {assoc }}$ is the contribution from the association sites.

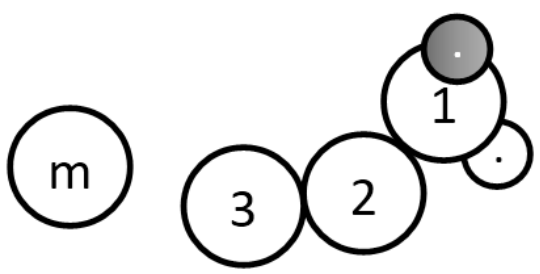

Figure 1. Scheme of an alkane molecule. This figure was adapted from Muller and Gubbins (2001). 
The chain formation term considers segments connected in linear chains (the same as polymer molecules) and the association term takes into account the real form of associating molecules Each nonassociating component requires three parameters, tangible and behaving orderly with molecular weight: $\sigma$, the molecular segment diameter (size parameter); $m$, the number of segments per molecule (chain length parameter), and $\varepsilon / k$, the segment dispersion energy - van der Waals attraction between each molecular segment (energy parameter). For self-association molecules, two more parameters must be calculated: $\kappa^{\mathrm{A}_{\mathrm{i}} \mathrm{Bi}}$, the volume association, and $\varepsilon^{\mathrm{A}_{\mathrm{i}} \mathrm{Bi}}$, the energy association (von Solms, 2004).

Due to this segregation of the Helmholtz energy into three factors, it was possible to attain many SAFT variants: each term can be treated separately and modified or new contributions can be added, for example polar and electrostatic terms. Gross and Sadowski (2000, 2001, 2002a, 2002b) proposed a model referred to as Perturbed-Chain SAFT (PCSAFT) using the second-order perturbation theory of Barker and Henderson (1967a, 1967b), which is based on a hard-chain fluid, instead of spherical molecules as in the other SAFT versions. Gross and Sadowski (2000) introduced a new dispersion term in order to model substances that did not present association sites, but that presented a relevant molecular structure with respect to attractive interactions, as both asphaltenes and polymer molecules.

Although many advances have been made in previous studies, the literature still lacks investigations focused on modeling of the asphaltene precipitation from crude oil. Most studies are focused on the description of asphaltene precipitation from model fluids, for example a solution of asphaltenes, heptane and toluene. Besides, very little is known when crude oils containing asphaltenes with very low molecular weights are employed, as in the case of Brazilian crude oils.

There is obviously a great interest in developing a general modeling approach able to provide proper description of the asphaltene precipitation. This task may be accomplished with the help of a thermodynamic model that adequately describes the asphaltene phase behavior. In this work, we intend to take a step further in the description of the precipitation of asphaltenes using the PC-SAFT theory and to present new experimental insights.
In this context, the objective of this paper is to study PC-SAFT applications for thermodynamic analysis and modeling of Brazilian crude oil and asphaltene systems. Specific objectives include (1) validate predictions of asphaltene density and crude oil boiling point elevation using PC-SAFT equations; (2) evaluate the precipitation curve of asphaltenes from a model oil with different $n$-alkanes by experimental methodology based on the literature; (3) study the asphaltene precipitation from crude oil and its stability.

\section{EXPERIMENTAL PROCEDURE}

\section{Chemicals}

The study of asphaltene precipitation in Brazilian light crude oil was performed using the following chemicals: n-hexane $(95.0 \%$ Neon $)$, n-heptane (Quimica Nova, PA) and toluene (Merck, PA). All of these materials were used as received.

\section{Asphaltene Extraction}

Experiments were performed at ambient conditions on two different systems: a real crude oil (Brazilian light crude oil) and a model oil, which was prepared by dissolving asphaltenes in toluene. The SARA analysis of the Brazilian crude oil was performed at Petrobras R\&D Center, to reproduce the crude oil components: saturates, $61.8 \mathrm{wt} \%$; aromatics, 18.1 wt $\%$; resins, $17.6 \mathrm{wt} \%$; and asphaltenes, $2.5 \mathrm{wt} \%$. Other physicochemical properties of crude oil are described in Table 1. Maltenes were separated from asphaltenes using two different solvents (n-hexane and $n$-heptane), following a procedure described by Hannisdal, Hemmingsen and Sjöblom (2005) and also used by Nascimento et al. (2016).

The oil sample was heated to $60{ }^{\circ} \mathrm{C}$ and then shaken for at least one hour to obtain a homogeneous solution. The n-alkane was added to the oil sample at ambient conditions and stirred for $24 \mathrm{~h}$ to allow the sample to reach equilibrium. The precipitated material was filtered using a vacuum system with a previously weighed $45 \mu \mathrm{m}$ membrane (Sartorius Stedium), and later washed with hot n-alkane $\left(60^{\circ} \mathrm{C}\right)$ to separate asphaltene materials from any material also precipitated. Once the n-alkane was evaporated in a desiccator and the asphaltenes were dried, the membrane was weighed and reported.

Dried asphaltenes were redissolved in toluene. This mixture containing asphaltenes from crude oil

Table 1. Brazilian crude oil properties.

\begin{tabular}{|c|c|c|c|c|c|c|c|}
\hline \multirow{2}{*}{$\begin{array}{c}\text { Density }^{\mathrm{a}} \\
\left(\mathrm{g} / \mathrm{cm}^{3}\right)\end{array}$} & \multirow{2}{*}{${ }^{\circ} \mathbf{A P I}{ }^{\mathbf{a}}$} & \multirow{2}{*}{ 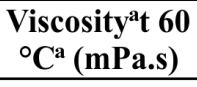 } & & \multicolumn{4}{|c|}{ SARA Classification } \\
\hline & & & & Saturates & Aromatics & Resins & Asphaltenes \\
\hline 0.8899 & 27.5 & 21.26 & wt $(\%)$ & $61.8^{\mathrm{a}}$ & $18.1^{\mathrm{a}}$ & $17.6^{\mathrm{a}}$ & $2.5^{\mathrm{a}}$ \\
\hline 0.8899 & 27.5 & 21.20 & Mw & $117^{\mathrm{a}}$ & $160^{\mathrm{a}}$ & $231^{\mathrm{a}}$ & $466^{b}$ \\
\hline
\end{tabular}

Source: (a) Petrobras R\&D Centerand(b) Nascimento et al. (2016). 
plus toluene was called "Model Oil" (Figure 2). The asphaltene precipitation from the "Model Oil" follows the same procedure as that from crude oil: the model mixture was precipitated with the corresponding n-alkane in different concentrations. The samples were shaken for one day to ensure the equilibrium was reached and finally filtered, enabling the separation of the asphaltene precipitated. The asphaltenes obtained after the precipitation and drying were then dissolved using different concentrations of toluene.

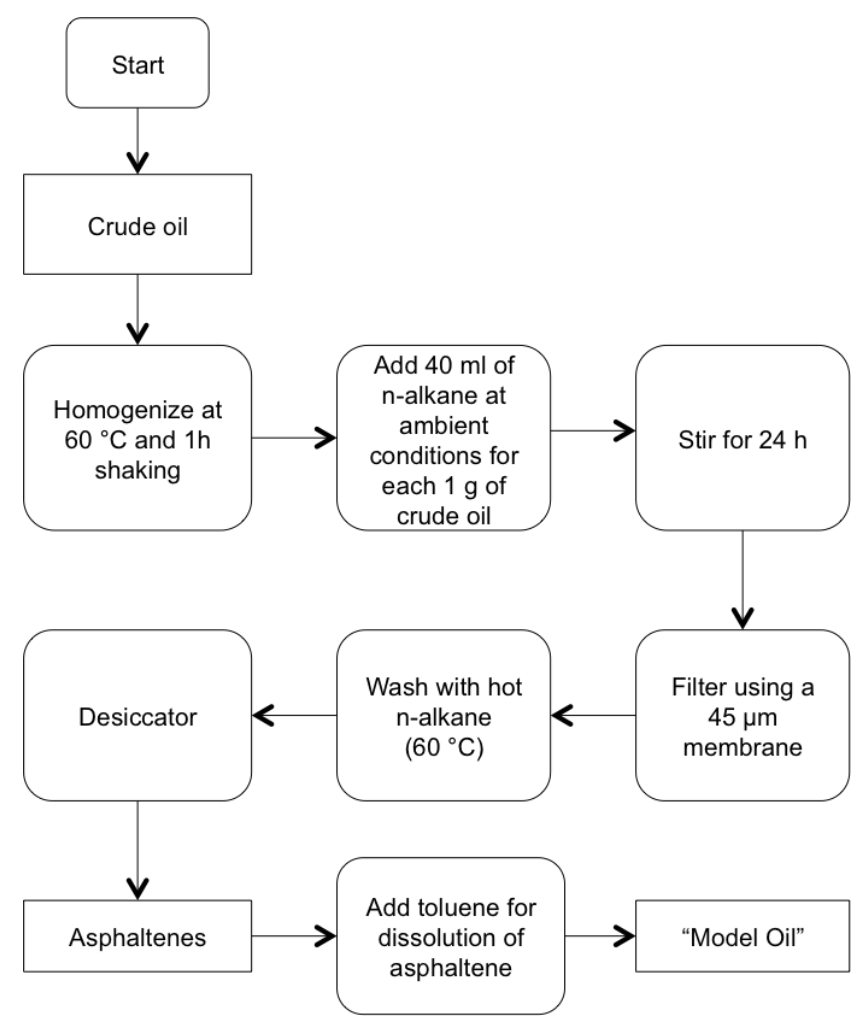

Figure 2. "Model Oil" preparation scheme.

\section{Density}

Density of asphaltenes was measured using an Anton Paar DMA 5000 high-precision vibrating tube densitometer with an accuracy of $\pm 1.10^{-6} \mathrm{~g} / \mathrm{cm}^{3}$, which was calibrated with ultrapure water and dry air. This equipment provides a high temperature accuracy $( \pm$ $0.001{ }^{\circ} \mathrm{C}$ ), whereas the value is controlled traceable to national standards by two integrated Pt 100 platinum thermometers. The equipment detects filling errors caused by gas bubbles present in the sample and exhibits live images that allow the operator to check whether the oscillating U-tube is completely filled so that accurate measurements can be carried out. After the thermostat is set to the desired temperature, approximately $1 \mathrm{~mL}$ is injected into the equipment, the temperature equilibrium is reached and then the display gives the density value. Densities were measured in a temperature range from $30^{\circ} \mathrm{C}$ to $80^{\circ} \mathrm{C}$ at atmospheric pressure.

Before conducting the asphaltene density measurement, the densitometer was also validated through the comparison between toluene densities measured using the equipment and data available in the literature. The procedure to determine the density of asphaltenes was as follows: dried asphaltene precipitated from crude oil was dissolved in toluene, here used as displacement fluid, in four different concentrations. Trapped air bubbles were eliminated by ultrasonication. It is also good to remember that the asphaltenes used in these experiments were precipitated using $n$-hexane.

\section{Boiling Point Elevation}

The experimental measurements were carried out using the apparatus proposed by Hoerning et al. (2016), as illustrated in Figure 3, to construct a boiling point elevation curve. A $250 \mathrm{ml}$ three neck flask was filled with 100 to $200 \mathrm{ml}$ of solution. Small pieces of porcelain were added to the flask before heating. The pieces of porcelain are necessary to provide extra surface area for the bubbles to form, allowing the gradual release of energy and thus avoiding bumping of liquid when the temperature rises. A thermistor (standard uncertainty of $0.1 \mathrm{~K}$ ) was connected to a temperature indicator (Novus, model N480D) and used for temperature measurement. The measuring junction of the thermistor was kept at about $1-2 \mathrm{~cm}$ below the surface of the liquid. The mixture was heated by a heating mantle and specific pressures were set with a Solab Cientifica vacuum pump, model SL60. The pressure of the system was monitored with a digital vacuum meter (Greisinger Eletronic $\mathrm{GmbH}$, model GDH12AN, with standard uncertainty of $0.1 \mathrm{kPa}$ ) and controlled using a needle valve, which was connected between the ebulliometer system and the pump. A condenser was connected to the central opening of the flash to assure that no vapor was lost during the boiling.

Since the controlled variable was the pressure, the strategy to collect the experimental data was to start

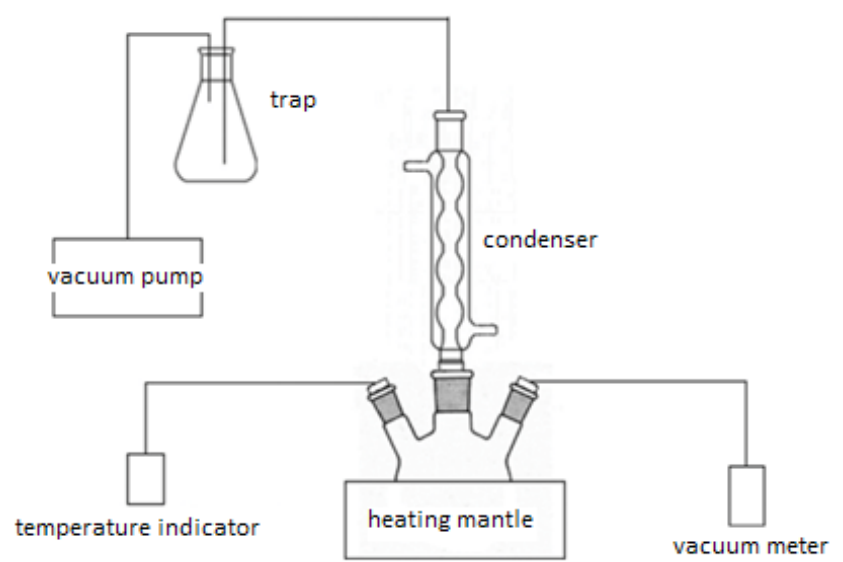

Figure 3. Schematic diagram of the ebulliometer used for measuring boiling point elevations, described by Hoerning et al. (2016). 
with the minimum value and perform increases up to atmospheric pressure. At a constant pressure, the solution was continually heated until the temperature became constant. The system was considered to be at equilibrium when the temperature of the liquid phase remained constant for at least $5 \mathrm{~min}$. After that, the temperature was measured every minute, five times, and the average of these measurements was considered. After six pressure steps had been measured, until atmospheric pressure, the heating was switched off.

Before conducting the crude oil boiling point measurement, the experimental methodology was validated. Temperatures of toluene and distilled water were measured over a certain pressure range and compared to the values in the NIST database. Boiling temperatures were obtained for solutions at different values of mass fraction of crude oil $(8,11,50$ and 70 $\mathrm{wt} \%$ ) and pressures (5.7 to $91.1 \mathrm{kPa}$ ).

\section{MODELING PROCEDURE}

Crude oil and asphaltene thermodynamic properties, as well as asphaltene precipitation using PC-SAFT Equation of State (PC-SAFT EoS) were modeled with a set of subroutines in Fortran 95 language, developed by and available in the Laboratory of Catalysis and Applied Thermodynamics (LACTA). The PC-SAFT subroutines for the fugacity coefficients were kindly provided by Prof. Walter Chapman's Group (Rice University, Houston, Texas, USA). The PC-SAFT methodology is described in details in the literature (Panuganti et al., 2012).

\section{PC-SAFT Parameter Estimation}

PC-SAFT focuses on non-associating components, so that there are just the three non-association parameters $(\sigma, \mathrm{m}$ and $\varepsilon / \mathrm{k})$ in this equation of state. As reported by other researchers (Tavakkoli et al., 2014; Sabeti et al., 2015) the association term in PC-SAFT can be set to zero in petroleum fluid characterization, since there is no association between the nonpolar hydrocarbon molecules.

Before thermodynamic phase equilibrium calculations, the petroleum mixtures are characterized so as to determine the molecular weights and the PCSAFT parameters for the pseudo-components (Ting et al., 2007). AlHammadi, Vargas and Chapman (2015) and Tavakkoli et al. (2014) calculated the PC-SAFT parameters from correlations presented by Punnapala and Vargas (2013). These correlations are summarized in Table 2, as functions of molecular weight, Mw; and the aromaticity factor (its limit values are 0 for n-alkanes and 1 for polynuclearomatics), $\gamma$.

\section{Phase Equilibrium Calculations}

Michelsen (1985) presented a method for the calculation of saturation temperatures or pressures for multicomponent mixtures with interaction in only a single variable. This method is summarized in the Appendix, as well as an algorithm for solving the bubble-point temperature problem using the Michelsen method and PC-SAFT equation of state to find the fugacity coefficient of components. Temperature, pressure and global composition are the input arguments.

\section{Asphaltene Precipitation Modeling}

To perform the modeling for the precipitation of asphaltenes, it was considered that asphaltenes are dissolved in crude oil. The precipitation process from the model oil (asphaltene+toluene) is treated as the traditional liquid-liquid phase separation. For the crude oil, it is considered that one liquid-phase is the phase rich in asphaltene and the other liquid-phase is characterized in terms of two pseudo-components: saturates and aromatics + resins $(\mathrm{A}+\mathrm{R})$. Using the same principle as $\mathrm{Li}$ and Firoozabadi ${ }^{14}$, aromatics and resins were considered as a pseudo-component, since both of them have polar-polar interaction with asphaltenes.

The algorithm of multiphase flash calculation presented in Figure 4 was used in this work to estimate asphaltene precipitation. Given the global composition $(\mathrm{z})$, temperature $(\mathrm{T})$ and pressure $(\mathrm{P})$ and for a one phase system $(n p=1)$ a phase stability test is executed. As the phase is unstable, meaning that there is asphaltene precipitation, the number of phases is assumed to be equal to $n p+1$ and a split calculation (with $n p+1$ phases) is performed. The phase stability test and the multiphase flash calculation are described in the literature by Ferrari et al. (2009).

\section{RESULTS AND DISCUSSION}

\section{Temperature-density diagram of pure toluene}

Before conducting the asphaltene density measurement, the equipment was validated, checking

Table 2. Correlations used to estimate the PC-SAFT parameters for pseudo-components as reported by Punnapala and Vargas (2013) and others researchers (Alhammadi et al., 2015; Tavakkoli et al., 2014).

\begin{tabular}{cc}
\hline $\begin{array}{c}\text { PC-SAFT } \\
\text { parameters }\end{array}$ & Correlation \\
\hline $\mathrm{m}$ & $(1-\gamma)(0.0257 \mathrm{Mw}+0.8444)+\gamma(0.0101 \mathrm{Mw}+1.7296)$ \\
$\sigma(\mathrm{A})$ & $(1-\gamma)(4.047-4.8013 \ln (\mathrm{mW}) / \mathrm{Mw})+\gamma(4.6169-93.98 / \mathrm{Mw})$ \\
$\varepsilon / \mathrm{k}(\mathrm{K})$ & $(1-\gamma)(\exp (5.5769-9.523 / \mathrm{Mw}))+\gamma\left(508-234100 / \mathrm{Mw}{ }^{1.5}\right)$ \\
\hline
\end{tabular}




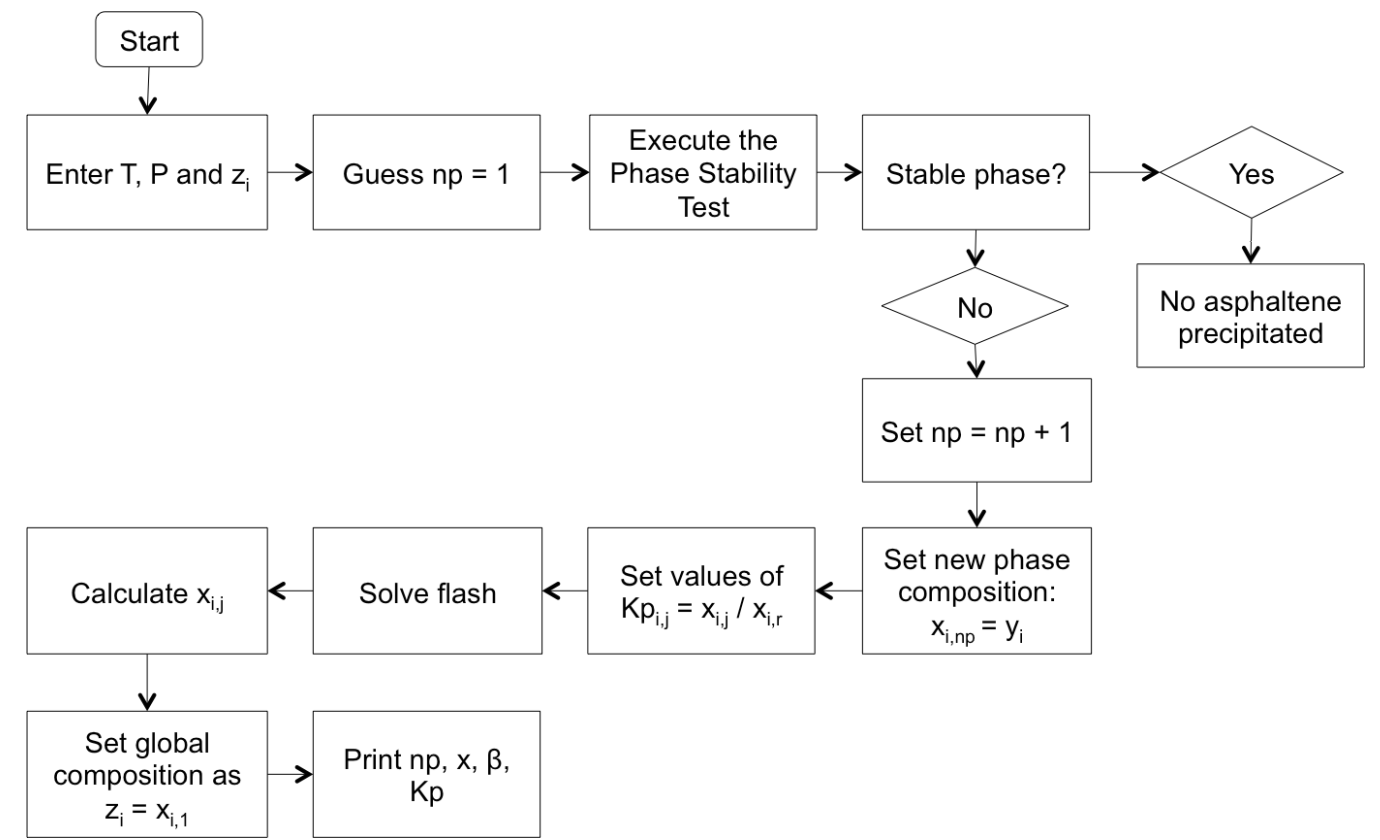

Figure 4. Algorithm for solving the phase equilibrium problem considering liquid-liquid equilibrium and using the PC-SAFT equation of state. Phase stability test and flash calculation are described by Ferrari et al. (2009).

if the density values of toluene obtained experimentally coincided with the reference values (NIST). As indicated by Table 3, experimental data obtained in this work are in good agreement with literature data, at ambient pressure and temperatures from $30^{\circ} \mathrm{C}$ up to $80^{\circ} \mathrm{C}$. It can also be noted that there is an increase in the relative error (calculated using Equation 2) as the temperature increases, which is the same observation made by Sabeti et al. (2015). However, the low value of MRE calculated by Equation 3 (mean relative errors, $0.003 \%$ ) allowed us to conclude that the experimental data are acceptable.

$$
\begin{aligned}
& \text { Relative error }(\%)=\left|\left(\mathrm{Y}_{\mathrm{i}}-\hat{\mathrm{Y}}_{\mathrm{i}}\right)\right| / \mathrm{Y}_{\mathrm{i}} \times 100 \\
& \mathrm{MRE}=\left[\Sigma\left|\left(\mathrm{Y}_{\mathrm{i}}-\hat{\mathrm{Y}}_{\mathrm{i}}\right)\right| / \mathrm{Y}_{\mathrm{i}} \times 100\right] / \mathrm{n}
\end{aligned}
$$

where $Y_{i}$ is the actual value of $n$ predictions and $\hat{Y}_{i}$ is the predicted or estimated value. In this case, $Y_{\mathrm{i}}$ is the experimental value and $\hat{Y}_{\mathrm{i}}$ is the value obtained from NIST.

PC-SAFT parameters were adjusted to obtain the best agreement for toluene density and, as shown in Table 3, the PC-SAFT EoS is able to provide a good prediction using the following set of parameters: $\mathrm{m}=$ $2.7616 ; \sigma=3.7316 \mathrm{~A}$; and $\varepsilon / \mathrm{k}=289.22 \mathrm{~K}$.

\section{Temperature-density diagram for asphaltene- toluene mixture}

Similar to the previous section, it is possible to evaluate the temperature-density diagram for a multicomponent fluid using the PC-SAFT EoS. For a twocomponent mixture of asphaltene and toluene with four different mass fractions of asphaltene, the result of the PC-SAFT modeling is compared with the experimental data. The aromaticity value of asphaltene was set to 0.35 as reported by Tavakkoli et al. (2014), the molecular weight of asphaltene is $466 \mathrm{~g} / \mathrm{mol}$ according to Nascimento et al. (2016) and the binary interaction parameter for asphaltene-toluene was set to 0.032. A

\begin{tabular}{|c|c|c|c|c|c|}
\hline \multicolumn{6}{|c|}{$P=680 \mathrm{mmHg}$} \\
\hline \multirow[b]{2}{*}{$\begin{array}{c}\text { Temperature } \\
\left({ }^{\circ} \mathrm{C}\right)\end{array}$} & \multirow{2}{*}{$\begin{array}{c}\text { Experimental } \\
\text { Density } \\
\left(\mathrm{g} / \mathrm{cm}^{3}\right)\end{array}$} & \multicolumn{2}{|c|}{ Literature } & \multicolumn{2}{|c|}{ Calculated } \\
\hline & & $\begin{array}{l}\text { Density } \\
\left(\mathrm{g} / \mathrm{cm}^{3}\right)\end{array}$ & $\begin{array}{c}\text { Relative Error } \\
(\%)\end{array}$ & $\begin{array}{l}\text { Density } \\
\left(\mathrm{g} / \mathrm{cm}^{3}\right)\end{array}$ & $\begin{array}{c}\text { Relative Error } \\
(\%)\end{array}$ \\
\hline 30.00 & 0.857573 & 0.857560 & 0.001516 & 0.847668 & 0.254237 \\
\hline 39.99 & 0.848193 & 0.848190 & 0.000354 & 0.838525 & 0.231794 \\
\hline 49.99 & 0.838736 & 0.838750 & 0.001669 & 0.829371 & 0.200774 \\
\hline 59.99 & 0.829189 & 0.829220 & 0.003738 & 0.820182 & 0.162195 \\
\hline 69.99 & 0.819543 & 0.819600 & 0.006955 & 0.810933 & 0.117645 \\
\hline 79.99 & 0.809811 & 0.809850 & 0.004816 & 0.801599 & 0.071569 \\
\hline MRE & & & 0.003175 & & 0.173036 \\
\hline
\end{tabular}

Table 3. Statistical evaluation between literature and experimental data for liquid density of pure toluene. 
comparison of the equation of state predictions and the experimental data for the asphaltene-toluene density is shown in Figure 5. As illustrated in the figure, the density data of the asphaltene-toluene mixture was enough to estimate the binary interaction parameter with reasonable accuracy. The resulting diagram of the PC-SAFT solution is in fairly good agreement with the experimental data: the mean relative error interval for the four different concentrations is from $0.09 \%$ to $0.18 \%$.

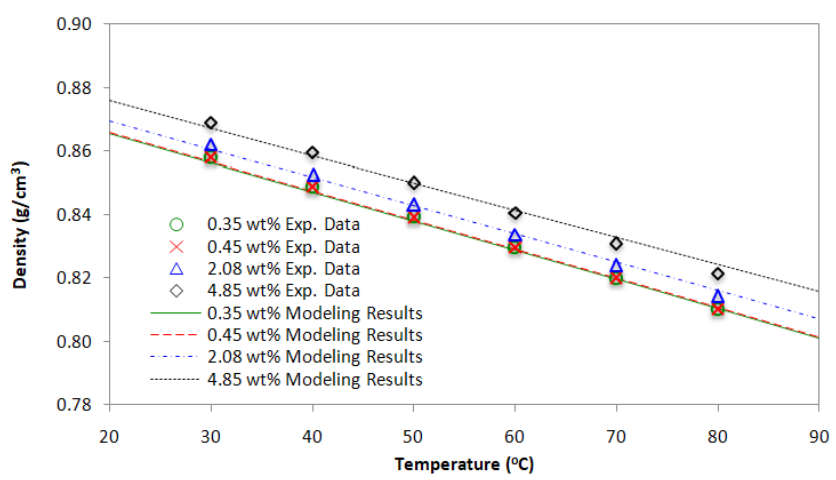

Figure 5. Temperature-density diagram for asphaltene diluted with toluene at different concentrations (asphaltene contents: $\odot,--, 0.35 \mathrm{wt} \% ; \times,---$, $0.45 \mathrm{wt} \% ; \Delta,-\cdot-\cdot-, 2.08 \mathrm{wt} \% ; \diamond, \cdots \cdot, 4.85 \mathrm{wt} \%)$ at ambient pressure. A comparison of the experimental data (symbols) to PC-SAFT correlation results (lines). Model parameters: asphaltene aromaticity $=0.35$ and binary interaction parameter $=0.032$.

\section{Boiling point elevation}

In order to check the reliability of the boiling point elevation measurement apparatus, the vapor pressure of pure toluene was measured. The mean relative error (MRE) between the experimental data and those published in the literature (NIST) was $2.40 \%$. This experiment was repeated using water, presenting a MRE of $3.47 \%$.These results are presented Table S1 of the Appendix and confirm that the apparatus is reliable and applicable for experimental measurements.

Table 4 reports the experimental data for the boiling point elevation of crude oil diluted at different concentration in toluene: $8.0 \mathrm{wt} \%, 11 \mathrm{wt} \%, 50 \mathrm{wt} \%$ and $70 \mathrm{wt} \%$. Figure 6 illustrates the experimental and

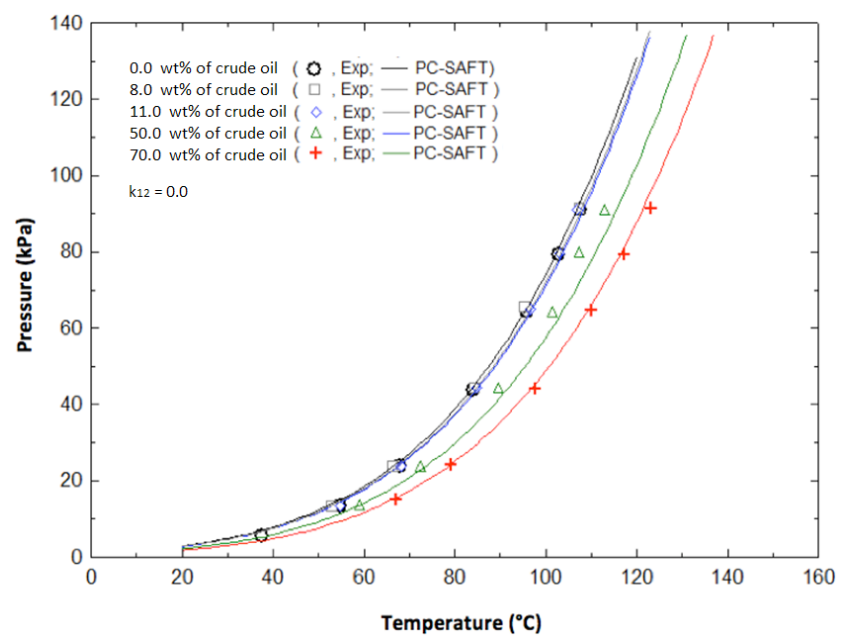

Figure 6. Boiling points of crude oil solution \{crude oil diluted with toluene (1) $\}$ at different concentrations (crude oil contents: $\odot, 0.0 \mathrm{wt} \% ; \square, 8.0 \mathrm{wt} \% ; \diamond, 11.0 \mathrm{wt} \%$; $\Delta, 50.0 \mathrm{wt} \% ;+, 70 \mathrm{wt} \%)$ at ambient pressure. Crude oil is represented by saturates (2), A+R (3) and asphaltenes (4). A comparison of the experimental data (symbols) to PC-SAFT correlation results (lines). Binary interaction parameters: toluene-saturates, $k_{12}=0.0$; toluene-A+R, $k_{13}=0.0$; toluene-asphaltene, $k_{14}=0.0320$.

modeling results. The PC-SAFT parameters of saturates and $\mathrm{A}+\mathrm{R}$ were estimated as a function of molecular weight and aromaticity. The binary interaction parameters for the system toluene (1) - crude oil; represented as three pseudo-components: saturates (2), $A+R(3)$ and asphaltenes (4); were analyzed in order to get the best match for boiling point elevation, comparing PC-SAFT modeling results with experimental data, except for toluene-asphaltene as defined before $\left(\mathrm{k}_{14}=0.032\right)$. The vapor-liquid behavior of toluenecrude oil mixture were well predicted without having to adjust any other binary parameter, meaning that $\mathrm{k}_{12 \text { - }}$ $=0.0$ and $\mathrm{k}_{13}=0.0$. In addition, it is important to note the ability of PC-SAFT to adjust $\mathrm{k}_{\mathrm{ij}}$ values using density data (in the case of the toluene-asphaltene parameter) and predicting phase equilibrium data.

\section{Asphaltene precipitation modeling}

Table 1 shows the SARA analysis fraction (in weight $\%$ ) of Brazilian crude oil. It also reports average

Table 4. Experimental data of boiling point elevation for crude oil diluted with toluene at different concentrations $(\mathrm{wt} \%)$.

\begin{tabular}{|c|c|c|c|c|c|c|c|c|c|}
\hline \multicolumn{10}{|c|}{ Concentration (wt \%) of crude oil in toluene } \\
\hline \multicolumn{2}{|c|}{$0.0 \mathrm{wt} \%$} & \multicolumn{2}{|c|}{$8.0 \mathrm{wt} \%$} & \multicolumn{2}{|c|}{$11.0 \mathrm{wt} \%$} & \multicolumn{2}{|c|}{$50.0 \mathrm{wt}^{\circ} \%$} & \multicolumn{2}{|c|}{$70.0 w t \%$} \\
\hline $\mathbf{P}(\mathbf{k P a})$ & $\mathrm{T}\left({ }^{\circ} \mathrm{C}\right)$ & $\mathbf{P}(\mathbf{k P a})$ & $\mathrm{T}\left({ }^{\circ} \mathrm{C}\right)$ & $\mathbf{P}(\mathbf{k P a})$ & $\mathrm{T}\left({ }^{\circ} \mathrm{C}\right)$ & $\mathbf{P}(\mathbf{k P a})$ & $\mathrm{T}\left({ }^{\circ} \mathrm{C}\right)$ & $\mathbf{P}(\mathbf{k P a})$ & $\mathrm{T}\left({ }^{\circ} \mathrm{C}\right)$ \\
\hline 8.4 & 44.0 & 13.4 & 53.1 & 13.4 & 54.9 & 13.5 & 59.3 & 14.9 & 67.1 \\
\hline 13.5 & 51.4 & 23.8 & 66.5 & 23.7 & 68.4 & 23.7 & 72.7 & 24.3 & 79.3 \\
\hline 24.0 & 62.9 & 44.3 & 84.3 & 44.2 & 84.9 & 44.2 & 89.8 & 44.2 & 97.9 \\
\hline 44.1 & 76.1 & 65.3 & 95.4 & 64.8 & 96.8 & 64.3 & 101.5 & 64.6 & 110.1 \\
\hline 69.3 & 86.8 & 91.1 & 107.6 & 79.6 & 103.2 & 79.7 & 107.6 & 79.4 & 117.4 \\
\hline 91.1 & 97.3 & & & 91.0 & 107.1 & 90.8 & 113.1 & 91.4 & 123.3 \\
\hline
\end{tabular}


molecular weight for the three crude oil pseudocomponents. In the modeling process, aromatics and resins are considered to be a single pseudo-component.

Different methods have been proposed to estimate the three PC-SAFT parameters for the pseudocomponents. Panuganti et al. (2012) tuned the asphaltene parameters to match the experimental asphaltene onset pressure. Punnapala and Vargas (2013) proposed a method in which molecular weight (relating the average molecular size of the fraction) and aromaticity (indicating the chemical nature of the pseudo-component) are used for the asphaltene fraction. Although Ting et al. (2007) defined aromaticity to be zero for poly-nuclear aromatic (PNA) and one for benzene derivatives, Punnapala and Vargas (2013) redefined aromaticity to be equal to zero for saturates and one for PNA. Consequently, the PCSAFT parameters for A $+\mathrm{R}$ and asphaltene fractions are linearly weighted by the corresponding aromatic parameters between the n-alkane components and PNA (Table 2). The aromaticity value of saturates is 0.0 and for aromatics+resins it was adjusted to 0.70 , as suggested by Tavakkoli et al. (2014) after they compared experimental and modeling results for densities of crude oil. Aromaticity value of asphaltene was adjusted to 0.35 as previously justified. Table 5 summarizes oil components and weight percent as well as model parameters used in this work. The PCSAFT parameters for non-associating compounds such as $n$-hexane and n-heptane were adopted from the literature (2001).

The estimation of binary interaction parameters from thermodynamic models is an important step in phase equilibrium modeling. Different strategies have been used to perform the binary parameter estimation, for example, by using a regression of either isothermal equilibrium data or critical point data (Corazza et al., 2004). In this work, the binary interaction parameters were adjusted to obtain the best agreement with experimental data. Table 6 reports the binary interaction parameters $\left(\mathrm{k}_{\mathrm{ij}}\right.$ value) used in this work. For the asphaltene-toluene pair, the $\mathrm{k}_{\mathrm{ij}}$ value was fitted based on the temperature-density diagram, presented above. For the following pairs, the $\mathrm{k}_{\mathrm{ij}}$ values were fitted based on boiling point elevation data: toluene-saturate and toluene-(A+R). The study of asphaltene precipitation from model oil was used to predict interaction parameters for $n$-hexane-asphaltene and $n$-heptane-asphaltene. The binary interaction parameters for the system n-alkanes-saturates and $\mathrm{n}$-alkanes- $(\mathrm{A}+\mathrm{R})$ are analyzed in order to obtain the best match for asphaltene precipitation from crude oil, through the comparison of PC-SAFT modeling results with experimental data.

\section{Asphaltene precipitation from Model Oil}

Asphaltene extracted from crude oil using the methodology presented in Figure 2 was dissolved in different amounts of toluene forming what was called "Model Oil". Two n-alkanes were used to precipitate asphaltene from this Model Oil: n-hexane and n-heptane.

The binary interaction parameters for the systems toluene(1)-n-hexane(2) and toluene(1)-n-heptane(3) were determined by fitting the vapor-liquid equilibrium experimental data (from the literature, Gmehling et al., 1997) of the binary component mixture, as suggested by Zhang, Pedrosa and Moorwood (2012). These relatively simple systems were better predicted using $\mathrm{k}_{12}=0.0082$ and $\mathrm{k}_{13}=0.0065$. The comparison of PC-SAFT predicted vapor-liquid equilibrium versus literature data for the systems toluene-n-alkanes and the influence of binary interaction parameters are presented in the Appendix (Figure S2 and Figure S3).

Figure 7 compares the experimental and modeling results of asphaltene precipitation by the addition of $n-C_{6}$. Different $k_{i j}$ values for the pair n-hexaneasphaltene were analyzed and a good prediction is

Table 5. Modeled crude oil composition and PC-SAFT parameters.

\begin{tabular}{ccccccc}
\hline Component & Mw (g/mol) & wt\% in crude oil & $\gamma$ & M & $\boldsymbol{\sigma}(\mathbf{A})$ & $\mathbf{\varepsilon} / \mathbf{k}(\mathbf{K})$ \\
\hline n-Hexane & 86 & - & 0 & 3.0576 & 3.7983 & 236.77 \\
n-Heptane & 100 & - & 0 & 3.4831 & 3.8049 & 238.40 \\
Toluene & 92 & - & 0 & 2.7616 & 3.7316 & 289.22 \\
Saturates & 117 & 61.8 & 0 & 3.8513 & 3.8516 & 243.59 \\
A + R & 188 & 35.7 & 0.70 & 4.2513 & 4.0571 & 367.69 \\
Asphaltenes & 466 & 2.5 & 0.35 & 10.5861 & 4.1347 & 337.94 \\
\hline
\end{tabular}

Table 6. Binary interaction parameters used for PC-SAFT modeling.

\begin{tabular}{|c|c|c|c|c|c|c|}
\hline Component & $n-C_{6}$ & n-C $\mathbf{C}_{7}$ & Toluene & Saturates & $\mathbf{A}+\mathbf{R}$ & Asphaltenes \\
\hline $\mathrm{n}-\mathrm{C}_{6}$ & 0 & & & & & \\
\hline $\mathrm{n}-\mathrm{C}_{7}$ & 0 & 0 & & & & \\
\hline $\begin{array}{l}\text { Toluene } \\
\text { Soturntes }\end{array}$ & 0.0082 & 0.0065 & 0 & & & \\
\hline $\begin{array}{c}\text { Saturates } \\
A+R\end{array}$ & -0.0050 & $\begin{array}{r}-0.0050 \\
-0.00\end{array}$ & 0 & 0 & 0 & \\
\hline Asphaltenes & 0.0500 & 0.0550 & 0.0320 & 0.0350 & 0.0050 & 0 \\
\hline
\end{tabular}




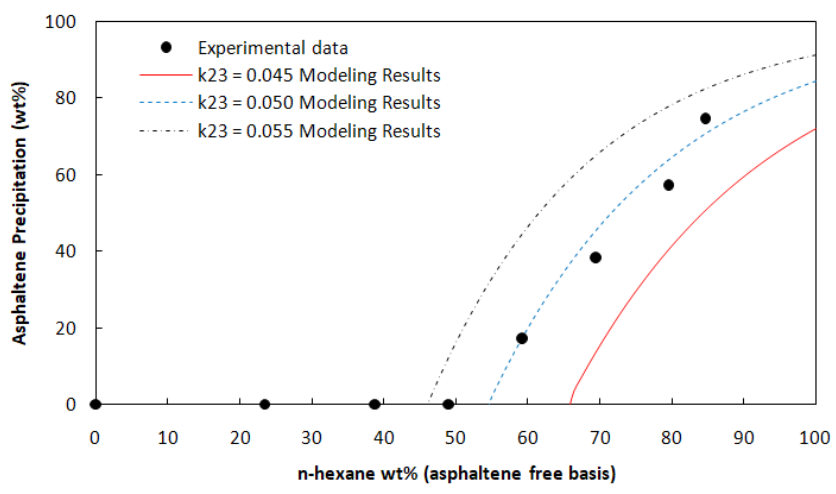

Figure 7. Asphaltene precipitation by the addition of n-hexane to the model oil \{toluene (1) + asphaltene (3) diluted with n-hexane (2)\}.A comparison of the experimental data (symbol) to PC-SAFT correlation results (lines) for different $k_{i j}$ values for $\mathrm{n}$-hexaneasphaltene. Binary interaction parameters: toluenen-hexane, $k_{12}=0.0082$ and toluene-asphaltene, $k_{13}=$ 0.0320

achieved when the binary interaction parameter is 0.050 . For asphaltene precipitation by the addition of $\mathrm{n}-\mathrm{C}_{7}$, the best match is reached when the $\mathrm{k}_{\mathrm{ij}}$ value for the binary n-heptane-asphaltene is 0.055 .

\section{Asphaltene precipitation from Crude Oil}

Figure 8 shows the asphaltene precipitation weight percentage as a function of solvent ratio under ambient conditions. It is evident that the carbon number of the n-alkane influences the amount of asphaltene precipitated. The molecular structure of n-alkanes has a strong effect on both the yield and the physicochemical properties of precipitated asphaltene. As the carbon number increases, the weight percentage of precipitated asphaltene decreases, as previously reported in the literature (Sabeti et al., 2015; Tavakkoli et al., 2014; Behbahani et al., 2011; Mohamed and Ramos, 1999). For this reason and also due to the

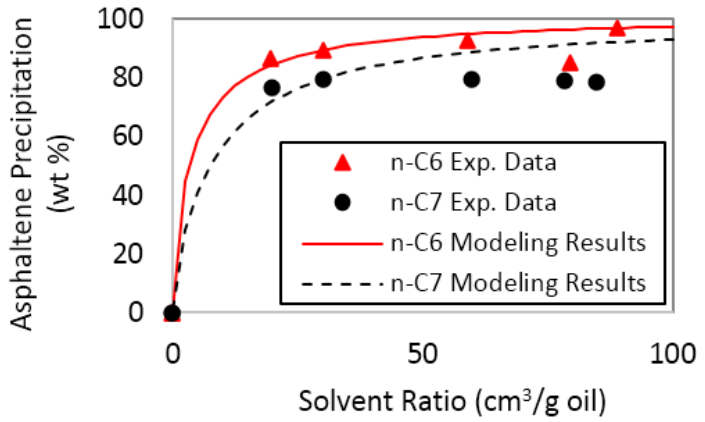

Figure 8. Asphaltene precipitation by the addition of n-hexane $(\boldsymbol{\Delta})$ and n-heptane $(\bullet)$ to crude oil. A comparison of the experimental data (symbols) to PCSAFT correlation results (lines).

fact that $\mathrm{n}-\mathrm{C}_{7}$ is denser and more viscous than $\mathrm{n}-\mathrm{C}_{6}$, which also affects the aggregation rate, it is possible to guarantee that $\mathrm{n}-\mathrm{C}_{6}$ precipitates more asphaltenes than $\mathrm{n}-\mathrm{C}_{7}$. To improve the results and to be able to predict the exact asphaltene onset point, experiments using low solvent ratio should be made, as reported by Zang et al. (2012).

Figure 8 exhibits the good agreement between experimental results and PC-SAFT modeling. Comparing the amount of precipitated asphaltene calculated by the PC-SAFT model with experimental results, mean relative errors of $3.75 \%$ and $10.25 \%$ are obtained for $n$-hexane and n-heptane solvents, respectively, as presented in Table 7. Ignoring the association term of PC-SAFT can be the motive of such errors. The modeling results show a better agreement for the $\mathrm{n}-\mathrm{C}_{6}$ experimental data, when compared to the heavier n-alkane. Tavakkoli et al. (2014) observed the same difference and justified it by the higher aggregation rate between precipitated asphaltenes when lighter n-alkanes were used.

León et al. (2000) determined the stability of different crude oils by means of the flocculation

Table 7. Experimental data for asphaltene precipitation of the crude oil with n-C6 and n-C7.

\begin{tabular}{|c|c|c|c|}
\hline \multicolumn{4}{|c|}{ n-hexane } \\
\hline $\begin{array}{c}\text { Solvent ratio } \\
\left(\mathrm{n}-\mathrm{C}_{6} \mathrm{~cm}^{3} / \mathrm{g} \text { of oil) }\right.\end{array}$ & $\begin{array}{l}\text { wt\% Asph. precipitated } \\
\text { (Exp. Data) }\end{array}$ & $\begin{array}{c}\text { wt\% Asph. precipitated } \\
\text { (Modeling Results) }\end{array}$ & $\begin{array}{c}\text { Relativeerror } \\
(\%)\end{array}$ \\
\hline 19.42 & 0.8649 & 0.8396 & 2.92 \\
\hline 29.85 & 0.8918 & 0.8918 & 0.01 \\
\hline 58.97 & 0.9254 & 0.9463 & 2.26 \\
\hline 79.60 & 0.8491 & 0.9621 & 13.31 \\
\hline 89.11 & 0.9650 & 0.9674 & 0.25 \\
\hline MRE & & & 3.75 \\
\hline \multicolumn{4}{|c|}{ n-heptane } \\
\hline $\begin{array}{c}\text { Solvent ratio } \\
\left(\mathrm{n}-\mathrm{C}_{7} \mathrm{~cm}^{3} / \mathrm{g} \text { of oil) }\right.\end{array}$ & $\begin{array}{l}\text { wt\% Asph. precipitated } \\
\text { (Exp. Data) }\end{array}$ & $\begin{array}{c}\text { wt\% Asph. precipitated } \\
\text { (Modeling Results) }\end{array}$ & $\begin{array}{c}\text { Relativeerror } \\
(\%)\end{array}$ \\
\hline 19.66 & 0.7610 & 0.7140 & 6.17 \\
\hline 30.00 & 0.7970 & 0.7927 & 0.54 \\
\hline 59.70 & 0.7928 & 0.8848 & 11.60 \\
\hline 78.43 & 0.7855 & 0.9101 & 15.86 \\
\hline 84.51 & 0.7825 & 0.9161 & 17.07 \\
\hline MRE & & & 10.25 \\
\hline
\end{tabular}


points and concluded that a crude oil becomes more stable when more n-alkane is added to initiate the precipitation. In this regard, the comparison of the results with those published by Tavakkoli et al. (2014) allows one to reach the conclusion that Brazilian asphaltenes are almost as stable as the asphaltenes from Middle East, even if there is a great difference between the molecular weight of these asphaltenes: the molecular weight of Brazilian asphaltenes is 466 $\mathrm{g} / \mathrm{mol}$ while those from the Middle East are around $2300 \mathrm{~g} / \mathrm{mol}$.

\section{CONCLUSIONS}

In this work, experimental measurements of the density of toluene+asphaltene solutions, boiling point elevation of crude oils + toluene, and asphaltene precipitation were obtained and were well correlated using the PC-SAFT equation of state. Although one of SAFT's major contribution is to include the oriented interaction (like hydrogen bonds), the dispersion energy seem to be the main interaction related to asphaltene precipitation. PC-SAFT has been successfully applied to non-associating molecules, which means that it is a very powerful tool and its terms can be used according to the modeling and theoretical approaches proposed for each system of interest. PC-SAFT was able to represent the asphaltene precipitation without using the association term. Probably the asphaltene "association" is other phenomena besides hydrogen bonds (the association term in the PC-SAFT).

First of all, the temperature-density diagram of pure toluene was experimentally obtained in order to check the applicability of the PC-SAFT equation of state to model liquid densities. The average relative error for liquid density was $0.17 \%$. The average relative error interval for asphaltene density ranges from $0.09 \%$ to $0.18 \%$, and the pseudo-experimental asphaltene density obtained at $50{ }^{\circ} \mathrm{C}$ is $1.08 \mathrm{~g} / \mathrm{cm}^{3}$.

The boiling point elevation apparatus was validated by collecting toluene experimental data and showed good agreement with vapor-liquid equilibrium data from the literature. Modeling results for crude oil boiling point elevation were similar to experimental data.

Asphaltenes were extracted from Brazilian crude oil based on solubility theory using $n-C_{6}$ and $n-C_{7}$ as precipitants and, as expected, the amount of asphaltene precipitated by the addition of $n-C_{6}$ was higher. The system were considered in a liquid-liquid state were one phase consists of asphaltenes while saturates and (resins+aromatics) constitute another. Furthermore, mean relative errors of $3.75 \%$ and $10.25 \%$ are obtained for $\mathrm{n}-\mathrm{C}_{6}$ and $\mathrm{n}-\mathrm{C}_{7}$ solvents, respectively. These results are encouraging and make the PC-SAFT strategy developed here an interesting tool to assess asphaltene behavior. Future studies will include a wider range of precipitation conditions in order to establish a reliable tool to infer asphaltene precipitation during oil production and transport.

\section{ACKNOWLEDGMENTS}

The authors thank CNPq and CAPES (Brazilian funding agencies) for supporting the present work and providing scholarships.

\section{ABBREVIATIONS}

API, American Petroleum Institute; EoS, Equation of State; LLE, Liquid-Liquid Equilibrium; MRE, Mean Relative Error; Mw, Molecular Weight; PC-SAFT, Perturbed-Chain Statistical Associating Fluid Theory; SARA, Saturates, Aromatics, Resins and Asphaltenes; VLE, Vapor-Liquid Equilibrium.

\section{REFERENCES}

Alhammadi, A. A., Vargas, F. M. and Chapman, W. G., Methodology for the Characterization and Modeling of Asphaltene Precipitation from Heavy Oils Diluted with n-Alkanes, Energy Fuels, 29, 2864-2875 (2015).

Barker, J. A. and Henderson, D., Perturbation Theory and Equation of State for Fluids: The Square-Well Potential, J. Chem. Phys., 47, 2856 (1967). https:// doi.org/10.1063/1.1712308

Barker, J. A. and Henderson, D., Perturbation Theory and Equation of State for Fluids. II. A Successful Theory of Liquids, J. Chem. Phys., 47, 4714 (1967b). https://doi.org/10.1063/1.1701689

Behbahani, T. J., Ghotbi, C., Taghikhani, V. and Shahrabadi, A., NOME, Scientia Iranica, 18, No. 6, 1384-1390 (2011). https://doi.org/10.1016/j. scient.2011.11.006

Cardoso, F. M. R., Carrier, H., Daridon, J. -L., Pauly, J. and Rosa, P. T. V., CO2 and Temperature Effects on the Asphaltene Phase Envelope as Determined by a Quartz Crystal Resonator, Energy Fuels, 28, No. 11, 6780-6787 (2014). https://doi.org/10.1021/ ef501488d

Chapman, W. G., Jackson, G. and Gubbins, K. E., Phase Equilibria of Associating Fluids: Chain Molecules with Multiple Bonding Sites, Mol. Phys., 65, No. 5, 1057-1079 (1988). https://doi. org/10.1080/00268978800101601

Chapman, W. G., Gubbins, K. E., Jackson, G. and Radosz, M., SAFT: Equation-of-state Solution Model for Associating Fluids, Fluid Phase Equilib., 52, 31-38 (1989). https://doi.org/10.1016/03783812(89)80308-5 
Chapman, W. G., Gubbins, K. E., Jackson, G. and Radosz, M., New Reference Equation of State for Associating Liquids, Ind. Eng. Chem. Res., 29, No. 8, 1709-1721 (1990). https://doi.org/10.1021/ ie $00104 \mathrm{a} 021$

Corazza, M. L., Filho, L. C., Oliveira, J. V. and Dariva, C., A robust strategy for SVL equilibrium calculation at high pressures, Fluid Phase Equilib., 221, 113-126 (2004). https://doi.org/10.1016/j. fluid.2004.03.016

Czarnecki, J. Proceedings of the 10th International Conference on Petroleum Phase Behavior and Fouling; Rio de Janeiro, Brazil, June 14-18 (2009).

Ferrari, J. C., Nagatani, G., Corazza, F. C., Oliveira, J. V. and Corazza, M. L., Application of Stochastic Algorithms for Parameter Estimation in the Liquid-Liquid Phase Equilibrium Modeling, Fluid Phase Equilib., 280, 110-119 (2009). https:/doi. org/10.1016/j.fluid.2009.03.015

Gholami, A., Moradi, S., Asoodeh, M., Bagheripour, P. and Vaezzadeh-Asadi, M., Asphaltene precipitation modeling through ACE reaping of scaling equation, Science China Chemistry, 57, No. 12, 1774-1780 (2014). https://doi.org/10.1007/s11426-014-5253-1

Ghonasgi, D. and Chapman, W. G., Theory and Simulation for Associating Fluids with Four Bonding Sites, Mol. Phys., 79, 291-311 (1993). https://doi.org/10.1080/00268979300101221

Gonzalez, D. L., Ting, P. D., Hirasaki, G. J. and Chapman, W. G., Precipitation of Asphaltene Instability under Gas Injection with the PC-SAFT Equation of State, Energy Fuels, 19, 1230-1234 (2005). https://doi.org/10.1021/ef049782y

Gross, J. and Sadowski, G., Application of Perturbation Theory to a Hard-Chain Reference Fluid: an Equation of State for Square-Well Chains, Fluid Phase Equilib., 168, 183-199 (2000). https://doi. org/10.1016/S0378-3812(00)00302-2

Gross, J. and Sadowski, G., Perturbed-Chain SAFT: An Equation of State Based on a Perturbation Theory for Chain Molecules, Ind. Eng. Chem. Res., 40, 1244-1260 (2001). https://doi.org/10.1021/ ie 0003887

Gross, J. and Sadowski, G., Modeling Polymer Systems Using the Perturbed-Chain Statistical Associating Fluid Theory Equation of State, Ind. Eng. Chem. Res., 41, 1084-1093 (2002a). https:// doi.org/10.1021/ie010449g

Gross, J. and Sadowski, G., Application of the Perturbed-Chain SAFT Equation of State to Associating Systems, Ind. Eng. Chem. Res., 41, 5510-5515 (2002b). https://doi.org/10.1021/ ie $010954 d$

Hannisdal, A., Hemmingsen, P. V. and Sjöblom, J., Group-Type Analysis of Heavy Crude Oils Using Vibrational Spectroscopy in Combination with Mutivariate Analysis, Ind. Eng. Chem. Res., 44, 1349-1357 (2005). https://doi.org/10.1021/ ie 0401354

Hoerning, A., Ribeiro, F. R. G., Filho, L. C., Luciano, M. L., Corazza, M. L. and Voll, F. A. P., Boiling Point Elevation of Aqueous Solution of Ionic Liquid from Diethanolamine Base and Carboxylic Acids, J. Chem. Thermodynamics, 98, 1-8 (2016). https://doi.org/10.1016/j.jct.2016.02.017

Holavko, M. F. and Kalyuzhnyi, Y. V. O., On the Effects of Association in the Statistical Theory of Ionic Systems. Analytic Solution of the PYMSA version of the Wertheim Theory, Mol. Phys., 73, No. 5, 1145-1157 (1991). https://doi. org/10.1080/00268979100101831

Joslin, C. G., Gray, C. G., Chapman, W. G. and Gubbins, K. E., Theory and Simulation of Associating Liquid Mixtures: Part II, Mol. Phys., 62, 843-860 (1987). https://doi.org/10.1080/00268978700102621

Kaminski, T. J., Fogler, H. S., Wolf, N., Wattana, P. and Mairal, A., Classification of Asphaltenes via Fractionation and the Effect of Heteroatom Content on Dissolution Kinetics, Energy Fuels, 14, 25-30 (2000). https://doi.org/10.1021/ef990111n

Kazeem, A. L., Crawshaw, J. P., Boek, E. S. and Vesovic, V., Experimental Investigation of Asphaltene Deposition in Capillary Flow, Energy Fuels, 26, 2145-2153 (2012). https://doi. org/10.1021/ef201874m

Kord, S., Miri, R., Ayatollahi, S. and Escrochi, M., Asphaltene Deposition in Carbonate Rocks: Experimental Investigation and Numerical Simulation, Energy Fuels, 26, 6186-6199 (2012). https://doi.org/10.1021/ef300692e

Leon, O., Rogel, E. and Espidel, J., Asphaltenes: Structural Characterization, Self Association and Stability Behavior, Energy Fuels, 14, 6-10 (2000). https://doi.org/10.1021/ef9901037

Li, Z. and Firoozabadi, A., Cubic-Plus Association Equation of State for Water-Containing Mixtures: Is "Cross Association"Necessary?,AlChE J., 55, No. 7, 1803-1813 (2009). https://doi.org/10.1002/ aic. 11784

Merino-Garcia, D. and Andersen, S. I., Isothermal Titration Calorimetry and Fluorescence Spectroscopy Study of Asphaltene Self-Association in Toluene and Interaction with a Model Resin, Petrol. Sci. Tech., 21, 507-525 (2003) https://doi. org/10.1081/LFT-120018535

Merino-Garcia, D. and Andersen, S. I., Thermodynamic Characterization of Asphaltene-Resin Interaction by Microcalorimetry, Langmuir, 20, 4559-4565 (2004). https://doi.org/10.1021/la0499315

Michelsen, M. L., Saturation Point Calculations, Fluid Phase Equilib., 23, 181-192 (1985). https://doi. org/10.1016/0378-3812(85)90005-6 
Mohamed, R. S. and Ramos, A. C. S., Aggregation Behavior of Two Asphaltenic Fractions in Aromatic Solvent, Energy Fuels, 13, 323-327 (1999). https:// doi.org/10.1021/ef9802072

Mousavi-Dehghani, S. A., Mirzayi, B. and Vafaie-Sefti, M., Polymer Solution and Lattice Theory Applications for Modeling of Asphaltene Precipitation in Petroleum Mixtures, Brazilian Journal of Chemical Engineering, 25, No. 3, 523-534 (2008). https://doi.org/10.1590/ S0104-66322008000300010

Moradi, S., Dabiri, M., Dabir, B., Rashtchian, D. and Emadi, M. A., Investigation of Asphaltene Precipitation in Miscible Gas Injection Processes: Experimental Study and Modeling, Brazilian Journal of Chemical Engineering, 29, No. 3, 665-767 (2012). https://doi.org/10.1590/S010466322012000300022

Moritis, G., Flow Assurance Challenges Production from Deeper Water, Oil Gas J., 99, 66-67 (2001).

Muller, E. A. and Gubbins, K. E., Molecular-Based Equations of State for Associating Fluids: A Review of SAFT and Related Approaches, Ind. Eng. Chem. Res., 40, No. 10, 2193-2211 (2001). https://doi. org/10.1021/ie000773w

Mullins, O. C. Petroleomics and Structure-Function Relation of Crude Oils and Asphaltene. In Asphaltenes, Heavy Oils, and Petroleomics, Mullins, O. C., Sheu, E. Y., Hammami, A., Marshall, A. G., Eds.; Springer, New York (2007). https://doi.org/10.1007/0-387-68903-6

Nascimento, P. T. H., Santos, A. F., Yamamoto, C. I., Tose, L. V., Barros, E. V., Gonçalves, G. R., Freitas, J. C. C., Vaz, B. G., Romão W. and Scheer, A. P., Fractionation of Asphaltene by Adsorption onto Silica and Chemical Characterization by Atmospheric Pressure Mass Spectrometry, Fourier Transform Infrared Spectroscopy Coupled to Attenuated Total Reflectance and Proton Nuclear Magnetic Resonance, Energy Fuels, 30(7), 5439-5448 (2016). https://doi.org/10.1021/acs.energyfuels.6b00523

Ndiaye, P. M., Lanza, M., Tavares, F. W., Dariva, C., Oliveira, D. and Oliveira, J. V., Phase Behavior of Olive and Soybean Oils in Compressed Propane and n-Butane, 23, No. 3, 405-415 (2006). https:// doi.org/10.1590/S0104-66322006000300014

Nellensteyn, F. J., The constitution of asphalt, Inst. Pet. Technol., 10, 311-325 (1924). https://doi. org/10.2307/1065499

Pfeiffer, J. P. and Saal, R. N. J., Asphaltic Bitume as Colloid System, J. Phys. Chem., 44, No. 2, 139-149 (1940). https://doi.org/10.1021/j150398a001

Punnapala, S. and Vargas, F. M., Revisiting the PCSAFT Characterization Procedure for an Improved Asphaltene Precipitation Prediction, Fuel, 108, 417-429 (2013). https://doi.org/10.1016/j. fuel.2012.12.058
Quintero, L. C. N. Fracionamento e análise de asfaltenos extraídos de petróleo brasileiro, Ph.D. Thesis, Federal Universityof Rio de Janeiro, Rio de Janeiro (2009).

Rajagopal, K. and Silva, S. M. C., An Experimental Study of Asphaltene Particle Sizes in n-HeptaneToluene Mixtures by Light Scattering, Brazilian Journal of Chemical Engineering, 21, No. 4, 601-609 (2004). https://doi.org/10.1590/S010466322004000400009

Sabeti, M., Rahimbakhsh, A., Nikkokar, M. and Mohammadi, A. H. J., Estimation of asphaltene precipitation and equilibrium properties of hydrocarbon fluid phases using the PC-SAFT equation of state, Mol. Liq., 209, 447-460 (2015). https://doi.org/10.1016/j. molliq.2015.05.003

Salahshoor, K., Zakeri, S., Mahdavi, S., Kharrat, R. and Khalifeh, M., Asphaltene Deposition Prediction Using Adaptive Neuro-Fuzzy Models Based on Laboratory Measurements, Fluid Phase Equilibria, 337, 89-99 (2013). https://doi.org/10.1016/j. fluid.2012.09.031

Santos, R. G., Loh, W., Bannwart, A. C. and Trevisan, O. V., An Overview of Heavy Oil Properties and its Recovery and Transportation Methods, Brazilian Journal of Chemical Engineering, 31, No. 3, 571-590 (2014). https://doi.org/10.1590/01046632.20140313s00001853

Sedghi, M. and Goual, L., PC-SAFT Modeling of Asphaltene Phase Behavior in the Presence of Nonionic Dispersants, Fluid Phase Equilib., 369, 86-94 (2014). https://doi.org/10.1016/j. fluid.2014.02.021

Speight, J. G. The Chemistry and Technology of Petroleum. 4. ed. Taylor and Francis Group (2006). https://doi.org/10.1201/9781420008388

Tavakkoli, M., Panuganti, S. R., Taghikhani, V., Pishvaie, M. R. and Chapman, W. G., Understanding the polydisperse behavior of asphaltenes during precipitation, Fuel, 117, 206-217 (2014). https:// doi.org/10.1016/j.fuel.2013.09.069

Thiyagarajan, P., Temperature-Dependent Structural Changes of Asphaltenes in 1-Methylnaphthalene, EnergyFuels, 9, 829-833 (1995). https://doi. org/10.1021/ef00053a014

Ting, P. D., Gonzalez, D. L., Hirasaki, G. J. and Chapman, W. G. Application of the PC-SAFT Equation of State to Asphaltene Phase Behavior. In: Asphaltenes, Heavy Oils, and Petroleomics; Mullins, O. C., Sheu, E. Y., Hammami, A. and Marshall, A. G. Springer: New York, pp 301-327 (2007). https://doi.org/10.1007/0-387-68903-6 12

Vargas, F. M., Gonzalez, D. L., Hirasaki, G. J. and Chapman, W. G., Modeling Asphaltene Phase Behavior in Crude Oil Systems Using the 
Perturbed Chain Form of the Statistical Associating Fluid Theory (PC-SAFT) Equation of State, Energy Fuels, 23, 1140-1146 (2009). https://doi. org/10.1021/ef8006678

Verdier, S., Carrier, H., Andersen, S. I. and Daridon, J.-L., Study of Pressure and Temperature Effects on Asphaltene Stability in Presence of $\mathrm{CO}_{2}$, Energy Fuels, 20, 1584-1590 (2006). https://doi. org/10.1021/ef050430g

Von Solms, N., Kouskoumvekaki, E., Lindvig, T. and Kontogeorgis, G., A novel approach to liquid-liquid equilibrium in polymer solutions with application to simplified PC-SAFT, Fluid Phase Equilib., 222, 87-93 (2004). https://doi.org/10.1016/j. fluid.2004.06.031

Zhang, X., Pedrosa, N. and Moorwood, T., Modeling Asphaltene Phase Behavior: Comparison of Methods for Flow Assurance Studies, Energy Fuels, 26, 2611-2620 (2012). https://doi.org/10.1021/ ef201383r

Wertheim, M. S. J., Fluids with Highly Directional Attractive Forces. I. Statistical Thermodynamics, Stat. Phys., 35 No. 1/2, 19-34 (1984a). https://doi. org/10.1007/BF01017362

Wertheim, M. S. J., Fluids with Highly Directional Attractive Forces. II. Thermodynamic Perturbation Theory and Integral Equations, Stat. Phys., 35, No. 1, 35-47 (1984b). https://doi.org/10.1007/ BF01017363

Wertheim, M. S. J., Fluids with Highly Directional Attractive Forces. III. Multiple Attraction Sites, Stat. Phys., 42, No. 3/4, 459-476 (1986a). https:// doi.org/10.1007/BF01127721

Wertheim, M. S. J., Fluids with Highly Directional Attractive Forces. IV. Equilibrium Polymerization, Stat. Phys., 42, No. 3/4, 477-492 (1986b). https:// doi.org/10.1007/BF01127722

\section{APPENDIX}

\section{Phase Equilimrium Calculation}

The following method was developed by Michelsen (1984) for the calculation of saturation temperatures or pressures for multicomponent mixtures.

The condition for phase equilibrium is based on the equality of chemical potentials of components present in the equilibrium phases or can be determined from the condition of equal fugacity in both phases for all components. Therefore, for a n-component mixture, there are $n$ unknown variables:

$\mathrm{f}_{\mathrm{i}}=\ln \mathrm{y}_{\mathrm{i}}+\ln \phi_{\mathrm{i}}(\mathrm{y})-\ln \mathrm{z}_{\mathrm{i}}-\ln \phi_{\mathrm{i}}(\mathrm{z})=0(\mathrm{i}=1, \ldots, \mathrm{nc})(\mathrm{S} .1)$

It is convenient to treat the mole fractions $y_{i}$ as independent, thus requiring another condition:
$\mathrm{f}_{\mathrm{N}+1}=1-\sum_{\mathrm{i}} \mathrm{y}_{\mathrm{i}}=0$

An equivalent equation can be obtained by a linear combination of Eq S.1 and S.2:

$\mathrm{Q}_{1}=1-\sum_{\mathrm{i}} \mathrm{y}_{\mathrm{i}}+\sum_{\mathrm{i}} \mathrm{y}_{\mathrm{i}}\left\{\ln \mathrm{y}_{\mathrm{i}}+\ln \phi_{\mathrm{i}}(\mathrm{y})-\ln \mathrm{z}_{\mathrm{i}}-\ln \phi_{\mathrm{i}}(\mathrm{z})\right\}=0(\mathrm{~S} .3)$

Solving the equations at $\mathrm{P}=\mathrm{P}_{\text {spec }}$ wherein $\mathrm{y}=\mathrm{y}^{*}$ and $\mathrm{T}=\mathrm{T}^{*}$. An approximation to $\mathrm{y}^{*}$ is $\hat{\mathrm{y}}$. Substituting this approximation in Eq S.3 and solving for the corresponding temperature $\mathrm{T}$, an approximate saturation temperature is obtained, which is more accurate than the approximation $\hat{y}$. However, the point $\left(\mathrm{T}, \mathrm{P}_{\text {spec }}\right)$ satisfying $\mathrm{Q}_{1}\left(\mathrm{~T}, \mathrm{P}_{\text {spec }}, \mathrm{y}\right)=0$ can not be located in the sigle-phase region for the mixture of composition $\mathrm{z}$. This implies negative values for the tangent plane distance and consequently the mixture is unstable.

An alternative form is obtained by isolating $\mathrm{y}_{\mathrm{i}}$ from Eq S.1 and substituting into Eq S.3:

$\mathrm{Q}_{2}(\mathrm{y}, \mathrm{T})=1-\sum_{\mathrm{i}} \mathrm{z}_{\mathrm{i}} \phi_{\mathrm{i}}(\mathrm{z}) / \phi_{\mathrm{i}}(\mathrm{y})$

At the equilibrium point between the phases with composition $\mathrm{z}$ and $\mathrm{y}$, Eq S.1 is satisfied:

$\frac{\mathrm{z}_{\mathrm{i}} \phi_{\mathrm{i}}(\mathrm{T}, \mathrm{P}, \mathrm{z})}{\phi_{\mathrm{i}}\left(\mathrm{T}, \mathrm{P}, \mathrm{y}^{*}\right)}=\mathrm{Y}_{\mathrm{i}}$

Using the Newton-Raphson method to correct $\mathrm{T}$ through an iterative calculation, Eq S.4 can be combined by direct substitution with Eq S.5, for adjusting y values:

$$
\mathrm{Y}_{\mathrm{i}}^{(\mathrm{k})}=\frac{\mathrm{z}_{\mathrm{i}} \phi_{\mathrm{i}}(\mathrm{T}, \mathrm{P}, \mathrm{z})}{\phi_{\mathrm{i}}\left(\mathrm{T}, \mathrm{P}, \mathrm{y}^{(\mathrm{k})}\right)}
$$

$\mathrm{Q}_{2}^{(\mathrm{k})}=1-\sum_{\mathrm{i}} \mathrm{Y}_{\mathrm{i}}^{(\mathrm{k})}$

$\mathrm{T}^{(\mathrm{k}+1)}=\mathrm{T}^{(\mathrm{k})}-\mathrm{Q}_{2}^{(\mathrm{k})} / \frac{\partial}{\partial \mathrm{T}}\left(\mathrm{Q}_{2}^{(\mathrm{k})}\right)$

$\mathrm{y}_{\mathrm{i}}^{(\mathrm{k}+1)}=\mathrm{Y}_{\mathrm{i}} / \sum_{\mathrm{j}} \mathrm{Y}_{\mathrm{j}}$

where $\mathrm{Y}$ is the auxiliary vector, $\mathrm{z}$ is the feed composition and $\mathrm{y}$ is the equilibrium phase composition and $\mathrm{Q}$ is the saturation point function. The procedure described by Eq S.6-S.9 is repeated until the convergence: $\mathrm{e}_{\mathrm{y}}=$ 
$\left\|\mathrm{y}^{\mathrm{k}+1}-\mathrm{y}^{\mathrm{k}}\right\|, \mathrm{e}_{\mathrm{T}}=\left\|\mathrm{T}^{\mathrm{k}+1}-\mathrm{T}^{\mathrm{k}}\right\|$ and $\mathrm{e}_{\text {Total }}=\mathrm{e}_{\mathrm{y}}+\mathrm{e}_{\mathrm{T}} \leq \varepsilon$, where $\varepsilon$ is the maximum allowed error, as the algorithm presented in Figure S1.

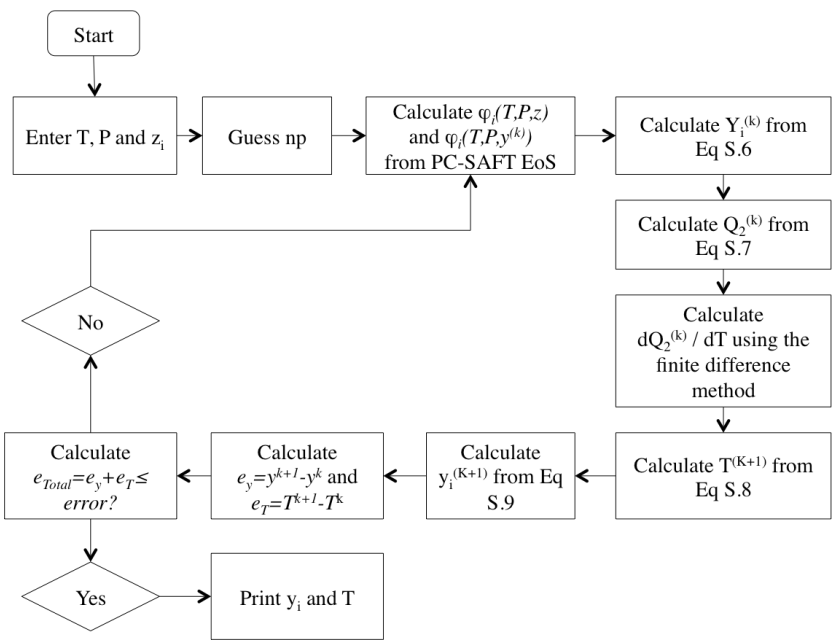

Figure S1. Algorithm for solving the bubble-point temperature problem using the Michelsen Method and PC-SAFT Equation of State.

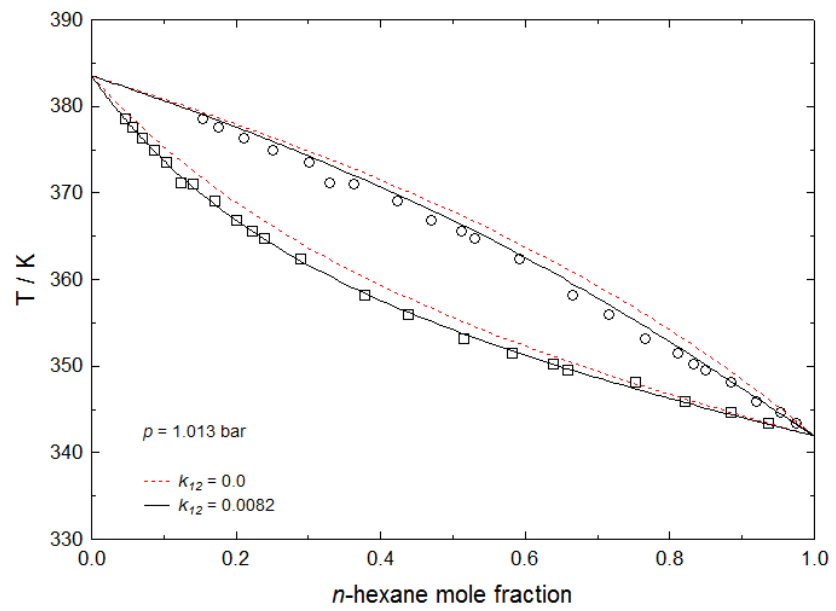

Figure S2. Comparison of PC-SAFT predicted vaporliquid equilibrium versus literature data (Dechema) for toluene(1)-n-hexane(2) with $\mathrm{k}_{12}=0.0$ (dashed line) and $\mathrm{k}_{12}=0.0082$ (continuous line) at $1.1013 \mathrm{bar}$.

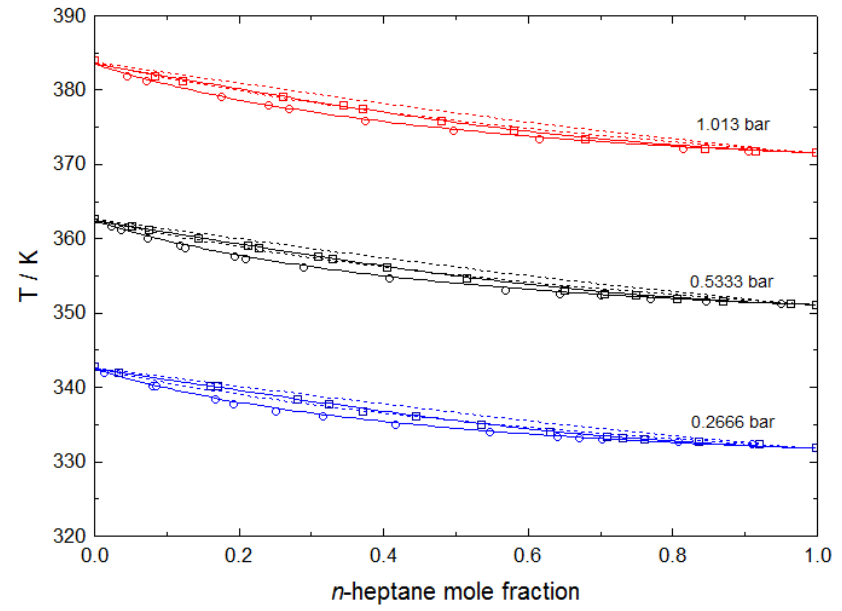

Figure S3. Comparison of PC-SAFT predicted vaporliquid equilibrium versus literature data (Dechema) for toluene(1)-n-heptane(2) with $\mathrm{k}_{12}=0.0$ (dashed line) and $\mathrm{k}_{12}=0.0065$ at $0.2666 \mathrm{bar}, 0.533$ bar and 1.1013 bar.

Table S1. Literature and experimental saturation temperature for water and toluene.

\begin{tabular}{cccc}
\hline $\begin{array}{c}\text { Pressure } \\
(\mathbf{k P a})\end{array}$ & $\mathbf{T}_{\text {EXP }}\left({ }^{\circ} \mathbf{C}\right)$ & $\left.\mathbf{T}_{\mathbf{L I T}}{ }^{\circ}{ }^{\circ} \mathbf{C}\right)$ & $\begin{array}{c}\text { Relative } \\
\text { error }(\mathbf{\%})\end{array}$ \\
\hline & & Water & \\
\hline 8.40 & 44.0 & 41.4 & 6.33 \\
13.45 & 51.4 & 49.3 & 4.19 \\
24.01 & 62.9 & 63.0 & 0.27 \\
44.11 & 76.1 & 80.0 & 4.93 \\
69.27 & 86.8 & 90.2 & 3.82 \\
90.18 & 97.3 & 94.9 & 2.49 \\
91.10 & 97.3 & 95.1 & 2.26 \\
MRE & & & 3.47 \\
\hline & & Toluene & \\
5.68 & 37.7 & 37.4 & 0.72 \\
13.50 & 54.7 & 50.5 & 8.33 \\
23.86 & 68.0 & 64.8 & 5.01 \\
43.71 & 84.0 & 84.1 & 0.17 \\
64.17 & 95.8 & 96.2 & 0.44 \\
79.27 & 102.8 & 102.1 & 0.66 \\
91.00 & 107.6 & 106.0 & 1.47 \\
MRE & & & 2.40 \\
\hline
\end{tabular}


